Check for updates

Cite this: J. Mater. Chem. B, 2020, 8, 136

Received 14th September 2019, Accepted 1st November 2019

DOI: $10.1039 / c 9 t b 02004 g$

rsc.li/materials-b

\section{"Tuning aggregative versus non-aggregative lectin binding with glycosylated nanoparticles by the nature of the polymer ligand" $\dagger$}

\author{
Panagiotis G. Georgiou, (D) a Alexander N. Baker, (D) ${ }^{a}$ Sarah-Jane Richards, (D) a \\ Antonio Laezza, ${ }^{a}$ Marc Walker (iD ${ }^{b}$ and Matthew I. Gibson (iD *ac
}

\begin{abstract}
Glycan-lectin interactions drive a diverse range of biological signaling and recognition processes. The display of glycans in multivalent format enables their intrinsically weak binding affinity to lectins to be overcome by the cluster glycoside effect, which results in a non-linear increase in binding affinity. As many lectins have multiple binding sites, upon interaction with glycosylated nanomaterials either aggregation or surface binding without aggregation can occur. Depending on the application area, either one of these responses are desirable (or undesirable) but methods to tune the aggregation state, independently from the overall extent/affinity of binding are currently missing. Herein, we use gold nanoparticles decorated with galactose-terminated polymer ligands, obtained by photo-initiated RAFT polymerization to ensure high end-group fidelity, to show the dramatic impact on agglutination behaviour due to the chemistry of the polymer linker. Poly( $\mathrm{N}$-hydroxyethyl acrylamide) (PHEA)-coated gold nanoparticles, a polymer widely used as a non-ionic stabilizer, showed preference for aggregation with lectins compared to poly( $\mathrm{N}$-(2-hydroxypropyl)methacrylamide) (PHPMA)-coated nanoparticles which retained colloidal stability, across a wide range of polymer lengths and particle core sizes. Using biolayer interferometry, it was observed that both coatings gave rise to similar binding affinity and hence provided conclusive evidence that aggregation rate alone cannot be used to measure affinity between nanoparticle systems with different stabilizing linkers. This is significant, as turbidimetry is widely used to demonstrate glycomaterial activity, although this work shows the most aggregating may not be the most avid, when comparing different polymer backbones/coating. Overall, our findings underline the potential of PHPMA as the coating of choice for applications where aggregation upon lectin binding would be problematic, such as in vivo imaging or drug delivery.
\end{abstract}

\section{Introduction}

Carbohydrates control and direct a myriad of biological processes including: cellular recognition, inflammation, signal transmission and infection of pathogens displayed by them. ${ }^{1,2}$ However, the intrinsic affinity of a glycan for a lectin target is typically very weak $\left(K_{\mathrm{d}} \sim \mathrm{mM}\right)$, which is compensated for on cell surfaces (or for example in glycan arrays ${ }^{3}$ ) by the multivalent presentation of multiple copies of the same glycan, which due to the cluster glycoside effect $^{4,5}$ results in entropy-enthalpy compensation

\footnotetext{
${ }^{a}$ Department of Chemistry, University of Warwick, Gibbet Hill Road, CV4 7AL, Coventry, UK. E-mail: m.i.gibson@warwick.ac.uk

${ }^{b}$ Department of Physics, University of Warwick, Gibbet Hill Road, CV4 7AL, Coventry, UK

${ }^{c}$ Warwick Medical School, University of Warwick, Gibbet Hill Road, CV4 7AL, Coventry, UK

$\dagger$ Electronic supplementary information (ESI) available. See DOI: 10.1039/ c9tb02004g
}

giving a non-linear increase in the observed binding affinity ( $K_{\mathrm{d}}$ can be $\mathrm{nM}$ or below). Due to this enhancement, there is significant interest in the development of polymeric and nanoparticulate glycosylated materials that benefit from the tuneable display of multiple glycans on scaffolds. For example, sialic acid polymers have been used as decoys for the influenza hemagglutinins enabling nM affinity, ${ }^{6,7}$ galactosylated polymers as inhibitors of the cholera toxin ${ }^{8,9}$ and dendrimers to target galectins ${ }^{10}$ and has been extensively reviewed. ${ }^{11-13}$

Glycomaterials are emerging as tools to modulate complex cellular function: Godula and co-workers remodelled neural progenitor cells with sulphated glycans to control their differentiation, ${ }^{14}$ mannosylated nanoparticles can potentiate vaccines ${ }^{15}$ and glycosylated nanomaterials have been used to aid cellular delivery. ${ }^{16-20}$ For instance, glucose- and galactosecoated iron oxide nanoparticles have been prepared and the influence of the glycan versus poly(ethylene glycol)-coating on the cellular uptake by several cell lines has been studied. ${ }^{17}$ 
Glycomaterials have been extensively explored for their application in anti-adhesion therapy to block infectious agents before they can engage the cell. ${ }^{11,21}$ Kitov et al. used starfish dendrimers to neutralize Shiga-toxin infection, ${ }^{22}$ and sialic acid polymers can inhibit hemagglutination by influenza. ${ }^{23}$ Many other glycoconjugates have been explored including galactosylated polymers for their interaction with the cholera toxin,,$^{8,9,24,25}$ fucosylated dendrimers with $\mathrm{LecB}^{26}$ (from Pseudomonas aeruginosa) and mannosylated polymers to target DC-SIGN, DC-SIGN-R and Langerin, which are all found on dendritic cells and form a key part of immune responses. ${ }^{27-29}$

In addition to binding or delivery, incorporating glycans into materials that can generate a signal output is a promising approach to develop new diagnostics and biosensors. ${ }^{30,31}$ Gold nanoparticles (AuNPs) in particular offer unique optical properties that have seen them widely employed for the design of biosensors and imaging agents. ${ }^{32-35}$ Their optical property of localized surface plasmon resonance (LSPR) is determined by the particle size and shape. As the interparticle distance decreases to less than that of the particle diameter, coupling and dipole-dipole interactions between the plasmons of neighboring particles result in a broadening and a shift to longer wavelengths of the surface plasmon absorption band, resulting in the AuNPs appearing blue as opposed to red when not aggregated.

Mirkin et al. exploited DNA-functionalized AuNPs for the colorimetric detection of bacterial DNA based on the 'red-blue' color shift upon aggregation of AuNPs. ${ }^{36}$ The display of glycans on the surface of AuNPs can mimic the cell-surface glycocalyx and hence are ideal probes of glycan recognition processes. In particular, lectins often display multiple binding sites, and hence multivalent glyconanoparticles readily aggregate in the presence of their lectin partner, enabling a simple, label-free read out of binding. ${ }^{37-40}$ A key challenge, however, in the design and application of colloidal biosensors is retaining colloidal stability in complex media and hence avoiding false positives. Field and co-workers used short PEG linkers to install sialic acids onto AuNPs for the discrimination between avian and human influenza. ${ }^{39}$ Gibson and co-workers have exploited reversible addition-fragmentation chain transfer (RAFT) polymerization to generate stabilizing poly( $N$-hydroxyethyl acrylamide) (PHEA) ligands for AuNPs: RAFT installs sulfur containing endgroups which have high affinity for gold surfaces. ${ }^{41-43}$ By using RAFT agents, with a pentafluorophenyl ester end-group, aminoglycans can be easily attached. The advantage of this controlled radical polymerization ${ }^{44}$ method is that the length of the linker can be tuned to achieve the delicate balance between stability (favored by longer chain length polymers) and aggregationresponse (favored by shorter chain lengths). ${ }^{45-48}$ This strategy is highly tunable, and has been used to probe the binding of a range of lectins, and also to probe carbohydrate-carbohydrate interactions. $^{49}$

The above examples make use of the aggregation of AuNPs to give a colorimetric response, but aggregation is not always desirable in other applications such as in vivo, where lectin binding, without macroscopic aggregation would be preferable. Hence there is a need to explore other polymeric coatings, to engineer the glycoparticle interface, and to optimize the solution stability. Biocompatible $\operatorname{poly}(\mathrm{N}$-(2-hydroxypropyl)methacrylamide) (PHPMA) is an important and frequently employed hydrophilic polymer which has been shown to be a viable alternative to PEG in many nanomedicine applications. ${ }^{50-52}$ PHPMA demonstrates similar biocompatibility profiles to PEG while also displaying pendent secondary hydroxyl groups that allow, for example, conjugation of targeting moieties and/or drugs via degradable linkages. ${ }^{53,54}$ PHPMA can be synthesized by a variety of polymerization techniques including conventional free radical polymerization, ${ }^{55}$ and reversible deactivation radical polymerization (RDRP) techniques such as atom transfer radical polymerization (ATRP), ${ }^{56}$ and reversible addition-fragmentation chain transfer (RAFT) polymerization of $\mathrm{N}$-(2-hydroxypropyl)methacrylamide (HPMA). ${ }^{57}$ Some examples of employing HPMA to synthesize glycan-decorated block-copolymers have already been reported. ${ }^{58-60}$

This work critically compares how methacrylamide, versus acrylamide-based polymer linkers impact the aggregative versus non-aggregative outcomes for glycosylated nanoparticles, with the aim to tune the aggregation independently from the extent of binding. Photo-initiated RAFT polymerization was used to synthesize variable molecular weight galactosamine-functional polymers which were assembled onto gold nanoparticles to give a library of 30 glyconanoparticles. Using the $N$-acetyl galactosamine binding lectin, soybean agglutinin (SBA), aggregation and binding were investigated using biolayer interferometry and UV-visible analysis. This revealed that PHPMA coatings result in nanoparticles with identical binding affinity to PHEA but avoided all aggregation, showing that subtle changes in the polymer linker can be used to tune the macroscopic response for specific applications. A detailed X-ray photoelectron spectroscopy (XPS) study indicated that intrinsic grafting density differences contribute to this tuneable behaviour, influenced by the chemistry of the linker.

\section{Experimental section}

\section{Materials and methods}

Materials and characterization techniques used are given in detail in the ESI. $\dagger$

\section{Synthetic procedures}

Synthesis of 2-(dodecylthiocarbonothioylthio)-2-methylpropanoic acid (DMP). 2-(Dodecylthiocarbonothioylthio)-2-methylpropanoic acid chain transfer agent (DMP CTA) was synthesized according to a previously described process. ${ }^{61}$ In particular, dodecane thiol (4.00 g, $4.73 \mathrm{~mL}, 19.76 \mathrm{mmol}$ ) was added dropwise to a stirred suspension of $\mathrm{K}_{3} \mathrm{PO}_{4}(4.20 \mathrm{~g}, 19.76 \mathrm{mmol})$ in acetone $(60 \mathrm{~mL})$ over 25 minutes. Carbon disulfide ( $4.10 \mathrm{~g}, 3.24 \mathrm{~mL}, 53.85 \mathrm{mmol})$ was subsequently added dropwise over $10 \mathrm{~min}$ and the solution turned bright yellow. After stirring for ten minutes 2-bromo2-methylpropionic acid (3.00 g, $17.96 \mathrm{mmol})$ was added to the reaction medium and a precipitation of $\mathrm{KBr}$ was noted. After stirring for 16 hours, the solvent was removed under reduced 
pressure and the residue was extracted into $\mathrm{CH}_{2} \mathrm{Cl}_{2}(2 \times 200 \mathrm{~mL})$ from $1 \mathrm{M} \mathrm{HCl}(200 \mathrm{~mL})$. The organic extracts were washed with water $(200 \mathrm{~mL})$ and brine $(200 \mathrm{~mL})$ and further dried over $\mathrm{MgSO}_{4}$. The solvent was removed under reduced pressure and the residue was purified by recrystallization in $n$-hexane yielding a bright yellow solid (2.36 g, $6.47 \mathrm{mmol}, 33 \%) .{ }^{1} \mathrm{H}$ NMR $(400 \mathrm{MHz}$, $\left.\mathrm{CDCl}_{3}\right): \delta(\mathrm{ppm}) 3.28\left(\mathrm{t}, 2 \mathrm{H}, \mathrm{S}-\mathrm{CH}_{2}-\mathrm{CH}_{2}\right) ; 1.73\left(\mathrm{~s}, 6 \mathrm{H}, \mathrm{S}-\mathrm{C}-\left(\mathrm{CH}_{3}\right)_{2}\right)$; $1.68\left(\mathrm{~m}, 2 \mathrm{H}, \mathrm{S}-\mathrm{CH}_{2}-\mathrm{CH}_{2}\right) ; 1.39\left(\mathrm{~m}, 2 \mathrm{H}, \mathrm{S}-\left(\mathrm{CH}_{2}\right)_{2}-\mathrm{CH}_{2}\right) ; 1.26$ (br s, $\left.\mathrm{S}-\left(\mathrm{CH}_{2}\right)_{3}-\left(\mathrm{CH}_{2}\right)_{8}\right) ; 0.88\left(\mathrm{t}, 3 \mathrm{H}, \mathrm{S}-\left(\mathrm{CH}_{2}\right)_{11}-\mathrm{CH}_{3}\right) .{ }^{13} \mathrm{C}$ NMR $(400 \mathrm{MHz}$, $\mathrm{CDCl}_{3}$ ): $\delta$ (ppm) 220.82 (C13); 55.54 (C14); 37.09 (C12); 31.93, 29.65, 29.57, 29.47, 29.36, 29.13, 22.70 (C2-9); 28.98 (C10); 27.82 (C11); 25.23 (C15); 14.14 (C1). FT-IR (neat): $\nu\left(\mathrm{cm}^{-1}\right) 2917$ (alkyl-H stretch); $1702(\mathrm{C}=\mathrm{O}$ stretch); 1064 ( $\mathrm{S}-(\mathrm{C}=\mathrm{S})-\mathrm{S}$ stretch). ESI-MS: $\mathrm{m} / \mathrm{z}$ $\left[\mathrm{C}_{17} \mathrm{H}_{32} \mathrm{O}_{2} \mathrm{~S}_{3}+\mathrm{Na}\right]^{+}$calc. $387.1 \mathrm{~g} \mathrm{~mol}^{-1}$, exp. $387.61 \mathrm{~g} \mathrm{~mol}^{-1}$.

Synthesis of 2-(dodecylthiocarbonothioylthio)-2-methylpropanoic acid pentafluorophenyl ester (PFP-DMP). 2-(Dodecylthiocarbonothioylthio)-2-methylpropanoic acid (1 g, $2.74 \mathrm{mmol}), \mathrm{N}-(3-$ dimethylaminopropyl)- $N$-ethylcarbodiimide hydrochloride (EDC) $(0.78 \mathrm{~g}, 4.1 \mathrm{mmol})$ and 4-(dimethylamino)pyridine (DMAP) (0.5 g, $4.1 \mathrm{mmol}$ ) were dissolved in $80 \mathrm{~mL}$ of dry dichloromethane (DCM). The resulting solution was then purged with $\mathrm{N}_{2}(\mathrm{~g})$ for $30 \mathrm{~min}$. Pentafluorophenol (1.56 g, $8.48 \mathrm{mmol}$ ) in $10 \mathrm{~mL}$ DCM was added. The esterification reaction proceeded with stirring at room temperature for $18 \mathrm{~h}$ under continuous $\mathrm{N}_{2}(\mathrm{~g})$ flow. The reaction was washed successively with $3 \mathrm{M} \mathrm{HCl}(100 \mathrm{~mL}), 1 \mathrm{M} \mathrm{NaHCO}$ $(100 \mathrm{~mL})$ and $0.5 \mathrm{M} \mathrm{NaCl}(100 \mathrm{~mL})$. The reaction was then dried over $\mathrm{MgSO}_{4}$, filtered and then concentrated in vacuo, yielding an oily-yellow product (0.998 g, $1.88 \mathrm{mmol}, 69 \%) .{ }^{1} \mathrm{H}$ NMR $(400 \mathrm{MHz}$, $\left.\mathrm{CDCl}_{3}\right): \delta(\mathrm{ppm}) 3.31\left(\mathrm{t}, 2 \mathrm{H}, \mathrm{S}-\mathrm{CH}_{2}-\mathrm{CH}_{2}\right) ; 1.86\left(\mathrm{~s}, 6 \mathrm{H}, \mathrm{S}-\mathrm{C}-\left(\mathrm{CH}_{3}\right)_{2}\right)$; $1.69\left(\mathrm{~m}, 2 \mathrm{H}, \mathrm{S}-\mathrm{CH}_{2}-\mathrm{CH}_{2}\right) ; 1.40\left(\mathrm{~m}, 2 \mathrm{H}, \mathrm{S}-\left(\mathrm{CH}_{2}\right)_{2}-\mathrm{CH}_{2}\right) ; 1.26$ (br s, $\left.\mathrm{S}-\left(\mathrm{CH}_{2}\right)_{3}-\left(\mathrm{CH}_{2}\right)_{8}\right) ; 0.88\left(\mathrm{t}, 3 \mathrm{H}, \mathrm{S}-\left(\mathrm{CH}_{2}\right)_{11}-\mathrm{CH}_{3}\right) \cdot{ }^{13} \mathrm{C} \mathrm{NMR}(400 \mathrm{MHz}$, $\mathrm{CDCl}_{3}$ ): $\delta$ (ppm) 219.94 (C13); 55.42 (C14); 37.18 (C12); 31.92, 29.63, 29.56, 29.45, 29.35, 29.24, 29.11, 22.70 (C2-9); 28.98 (C10); 27.83 (C11); 25.44 (C15); 14.12 (C1). ${ }^{19} \mathrm{~F} \mathrm{NMR} \mathrm{(400} \mathrm{MHz,} \mathrm{CDCl}_{3}$ ): $\delta$ (ppm) -151.5 (d, 2F, ortho F); -157.7 (t, F, para F); -162.4 (t, 2F, meta F). FT-IR (neat): $\nu\left(\mathrm{cm}^{-1}\right) 2923$ (alkyl-H stretch); 1780 $\left(\mathrm{C}_{6} \mathrm{~F}_{5} \mathrm{C}=\mathrm{O}\right) ; 1517\left(-\mathrm{C}_{6} \mathrm{~F}_{5}\right) ; 1064(\mathrm{~S}-(\mathrm{C}=\mathrm{S})-\mathrm{S})$.

Photo-polymerization of $\mathrm{N}$-(2-hydroxypropyl)methacrylamide (HPMA) using 2-(dodecylthiocarbonothioylthio)-2-methylpropanoic acid pentafluorophenyl ester (PFP-DMP). The following procedure describes a reaction for [monomer]:[CTA] ratio of 40. In a typical reaction, $N$-(2-hydroxypropyl)methacrylamide (HPMA) $(0.43 \mathrm{~g}$, $3.01 \mathrm{mmol}$ ), 2-(dodecylthiocarbonothioylthio)-2-methylpropanoic acid pentafluorophenyl ester (PFP-DMP) $(0.04 \mathrm{~g}, 0.075 \mathrm{mmol})$ were dissolved in 50:50 dioxane: methanol solution $(2 \mathrm{~mL})$ in a vial. The resulting solution was degassed by sparging with $\mathrm{N}_{2}(\mathrm{~g})$ for $15 \mathrm{~min}$ and the sealed vial was incubated at $37{ }^{\circ} \mathrm{C}$ with magnetic stirring under $460 \mathrm{~nm}$ light irradiation for $120 \mathrm{~min}$. After that time, an aliquot of crude polymerization mixture was taken for ${ }^{1} \mathrm{H}$ NMR in methanol- $d_{4}$ for conversion and $M_{\mathrm{n}, \mathrm{NMR}}$ analysis. The reaction was rapidly cooled in liquid nitrogen and precipitated into diethyl ether. The polymer was re-precipitated into diethyl ether from methanol twice to yield a yellow polymer product that was further dried under vacuum. The same procedure was followed for [monomer]:[CTA] ratios of 60, 80, 100 and 120. Conversions were calculated using ${ }^{1} \mathrm{H}$ NMR spectroscopy by comparing the integrations of the HPMA monomer signals $(\delta 5.73 \mathrm{ppm})$ with those of the corresponding signals of the polymer $\left(\delta 1.31-1.04 \mathrm{ppm}, \mathrm{CH}_{3}\right.$ of PHPMA backbone and $\mathrm{CH}_{3}$ of PHPMA side chain). $M_{\mathrm{n}, \mathrm{NMR}}$ was calculated by end-group analysis by comparing the integrations of the $-\mathrm{CH}_{3}$ signals $(\delta 0.92 \mathrm{ppm})$ of dodecyl end-group with those of the corresponding signals of the polymer $(\delta 1.31-1.04 \mathrm{ppm}) .{ }^{1} \mathrm{H} \mathrm{NMR}\left(400 \mathrm{MHz}, \mathrm{CD}_{3} \mathrm{OD}\right): \delta(\mathrm{ppm})$ 7.53 (br m, NH of PHPMA side chain), 3.88 (br s, CH of PHPMA side chain), 3.19-3.02 (br m, $\mathrm{CH}_{2}$ of PHPMA sidechain), 2.05-1.79 (br m, $\mathrm{CH}_{2}$ of PHPMA backbone), 1.31-1.04 (br m, $\mathrm{CH}_{3}$ of PHPMA backbone and $\mathrm{CH}_{3}$ of PHPMA side chain), 0.92 (t, 3H, $\mathrm{CH}_{2}-\mathrm{CH}_{2}-$ $\mathrm{CH}_{3}$ of dodecyl end-group).

FT-IR (neat): $\nu\left(\mathrm{cm}^{-1}\right) 3300(\mathrm{~N}-\mathrm{H}$ and $\mathrm{O}-\mathrm{H}$ stretch); 2920 (alkyl C-H stretch); $1775\left(\mathrm{C}_{6} \mathrm{~F}_{5} \mathrm{C}=\mathrm{O}\right.$ stretch); 1630 (amide $\mathrm{C}=\mathrm{O}$ stretch); 1518 (N-H bend); 1443 (alkane); 1200 (C-O stretch); 1080 (C-O stretch); 993 (C-F stretch).

Photo-polymerization of $\mathrm{N}$-(2-hydroxyethyl)acrylamide (HEA) using 2-(dodecylthiocarbonothioylthio)-2-methylpropanoic acid pentafluorophenyl ester (PFP-DMP). The following procedure describes a reaction for [monomer]:[CTA] ratio of 100 repeat units. In a typical reaction, $N$-(2-hydroxyethyl)acrylamide (HEA) (0.868 g, $7.54 \mathrm{mmol}$ ), 2-(dodecylthiocarbonothioylthio)-2-methylpropanoic acid pentafluorophenyl ester (PFP-DMP) (0.04 g, $0.075 \mathrm{mmol}$ ) were dissolved in 50:50 dioxane : methanol solution $(3.6 \mathrm{~mL})$ in a vial. The resulting solution was degassed by sparging with $\mathrm{N}_{2}(\mathrm{~g})$ for $15 \mathrm{~min}$ and the sealed vial was incubated at $37{ }^{\circ} \mathrm{C}$ with magnetic stirring under $460 \mathrm{~nm}$ light irradiation for $120 \mathrm{~min}$. After that time, an aliquot of crude polymerization mixture was taken for ${ }^{1} \mathrm{H}$ NMR in methanol- $d_{4}$ for conversion and $M_{\mathrm{n}, \mathrm{NMR}}$ analysis. The reaction was rapidly cooled in liquid nitrogen and precipitated into diethyl ether. The polymer was re-precipitated into diethyl ether from methanol twice to yield a yellow polymer product which was further dried under vacuum. Same procedure was followed for [monomer]:[CTA] ratios of 140, 160, 180 and 200. Conversions were calculated using ${ }^{1} \mathrm{H}$ NMR spectroscopy by comparing the integrations of the HEA monomer signals $(\delta 5.67 \mathrm{ppm}$ ) with those of the corresponding signals of the polymer ( $\delta 2.22-2.04 \mathrm{ppm}, \mathrm{CH}$ of PHEA backbone). $M_{\mathrm{n}, \mathrm{NMR}}$ was calculated by end-group analysis by comparing the integrations of the $-\mathrm{CH}_{3}$ signals $(\delta 0.92 \mathrm{ppm})$ of dodecyl end-group with those of the corresponding signals of the polymer ( $\delta$ 2.22-2.04 ppm). ${ }^{1} \mathrm{H}$ NMR (400 MHz, $\mathrm{CD}_{3} \mathrm{OD}$ ): $\delta$ (ppm) 8.15-8.03 (br m, NH of PHEA side chain), 3.89-3.13 (br $\mathrm{m}, \mathrm{NH}-\mathrm{CH}_{2}$ and $\mathrm{CH}_{2}-\mathrm{OH}$ of PHEA side chain), 2.35-2.05 (br m, $\mathrm{CH}$ of PHEA backbone), 1.851.31 (br m, $\mathrm{CH}_{2}$ of PHEA backbone), 0.92 (t, 3H, $\mathrm{CH}_{2}-\mathrm{CH}_{3}$ of dodecyl end-group). FT-IR (neat): $\nu\left(\mathrm{cm}^{-1}\right) 3300(\mathrm{~N}-\mathrm{H}$ and $\mathrm{O}-\mathrm{H}$ stretch); 2868 (alkyl C-H stretch); $1772\left(\mathrm{C}_{6} \mathrm{~F}_{5} \mathrm{C}=\mathrm{O}\right.$ stretch); 1638 (amide $\mathrm{C}=\mathrm{O}$ stretch); 1544 ( $\mathrm{N}-\mathrm{H}$ bend); 1438 (alkane); 1216 (C-O stretch); 1060 (C-O stretch); 950 (C-F peak on shoulder of 1060 peak).

End-group modification of PFP-poly( $N$-(2-hydroxypropyl)methacrylamide) (PFP-PHPMA) and PFP-poly( $N$-hydroxyethyl acrylamide) (PFP-PHEA) homopolymers using galactosamine. In a typical reaction, PFP-PHPMA ${ }_{25}(100 \mathrm{mg}, 0.024 \mathrm{mmol})$, galactosamine hydrochloride $(26.2 \mathrm{mg}, 0.122 \mathrm{mmol})$ were dissolved in $5 \mathrm{~mL}$ DMF with $0.05 \mathrm{M}$ triethylamine (TEA) $(50 \mu \mathrm{L})$. 
The reaction was stirred at $50{ }^{\circ} \mathrm{C}$ for $16 \mathrm{~h}$. The polymer was precipitated into diethyl ether from methanol three times and dried under vacuum. ${ }^{19} \mathrm{~F}-\mathrm{NMR}$ and IR analysis indicated loss of $\mathrm{C}=\mathrm{O}$ stretch corresponding to the PFP ester.

Gold nanoparticle functionalization. Approximately $1 \mathrm{mg}$ of the desired thiol-terminated polymer (Gal-PHPMA and Gal-PHEA) was added to a micro-centrifuge tube and dissolved in $100 \mu \mathrm{L}$ of high-purity water. $900 \mu \mathrm{L}$ of the citrate-stabilized gold nanoparticle solution was added to this tube (20, 30 and $40 \mathrm{~nm} \mathrm{NP}$ solution) that was then agitated for $30 \mathrm{~min}$ in the absence of light. To remove excess polymer, the particles were centrifuged and following careful removal of the supernatant, the particles were then redispersed in $1 \mathrm{~mL}$ of MilliQ water and the centrifugation-resuspension process repeated for a total of 3 cycles. After the final cycle the particles were dispersed in $1 \mathrm{~mL}$ of MilliQ water for future use. TEM, DLS, UV-VIS and zeta potential analyses were performed on the samples after dilution to an appropriate analysis concentration.

\section{Results and discussion}

To obtain the desired panel of glycosylated AuNPs, photoinitiated reversible addition-fragmentation chain-transfer (photo-RAFT) polymerization was employed. RAFT installs sulfur containing end-groups suitable for conjugation to AuNPs, and also enables installation of a glycan conjugation unit at the opposing end-group. ${ }^{45,62}$ To enable the role of coating on outputs to be evaluated, two different water soluble, non-ionic, polymers were chosen; $N$-hydroxyethyl acrylamide (HEA) and $N$-(2-hydroxypropyl)methacrylamide (HPMA). Rather than traditional thermal RAFT polymerization, photo-RAFT was chosen as it removes the need for heating, it is extremely convenient to undertake in the laboratory and as no external radical source is used, end-group fidelity is maximized. ${ }^{63,64}$ To the best of our knowledge, this is the first report of HPMA monomer being used to prepare well-defined homopolymers by photo-RAFT.

Using 2-(dodecylthiocarbonothioylthio)-2-methylpropanoic acid (PFP-DMP) chain transfer agent (CTA), (see Experimental section for detailed synthetic procedure) as the RAFT agent (suitable for (meth)acrylamide monomers), a range of PHEA and PHPMA telechelic homopolymers with [M]: [CTA] ratios between 25 and 100 were prepared. The polymerization reactions were carried out under $460 \mathrm{~nm}$ visible-light irradiation at $37{ }^{\circ} \mathrm{C}$ (under $\mathrm{N}_{2}$ atmosphere) in the absence of a photoinitiator or catalyst for $2 \mathrm{~h}$ using a mixture of methanol:dioxane (1:1) as the solvent (Scheme 1). Polymerization was stopped at less than $100 \%$ conversion to maximise the retention of end-groups. Size exclusion chromatography (SEC) analysis in DMF with $5 \mathrm{mM} \mathrm{NH}_{4} \mathrm{BF}_{4}$ revealed narrow monomodal molecular weight distribution peaks of low dispersity for both PHPMA and PHEA homopolymers (Fig. 1).

${ }^{1}$ H-NMR spectroscopy in methanol- $d_{4}$ was used for the determination of the average degree of polymerization (DP) of the final purified homopolymers by comparing the integral ratio of the peak corresponding to $-\mathrm{CH}_{3}$ group of dodecyl endgroup at $0.92 \mathrm{ppm}$ to the peak of $-\mathrm{CH}$ proton of PHPMA side chain at $3.88 \mathrm{ppm}$ or $-\mathrm{CH}$ proton of PHEA backbone at 2.05-2.35 ppm (Fig. S1, ESI $\dagger$ ). In all cases, low dispersity values and control of $M_{\mathrm{n}}$ was achieved, indicating a controlled photopolymerization. Table 1 shows the polymers synthesized and their characterization data. Incorporation of the PFP-group into polymers was confirmed via ${ }^{19} \mathrm{~F}$ NMR and FT-IR analysis (Fig. S3I and S4, ESI $\dagger$ ), showing retention of the group during polymerization. Finally, to examine potential lower critical solution temperature (LCST) behavior for both type of polymers, absorbance points were collected upon heating up to $60{ }^{\circ} \mathrm{C}$ in PBS buffer (Fig. S2, ESI $\dagger$ ). In both cases, no change in absorbance was detected confirming that the polymers are soluble across a range of temperature and saline conditions, which is essential for ruling out false-positives for binding in the lectin binding assays (below).

Glycan installation at the end groups of both PHPMA/PHEA homopolymers was achieved by reaction of the PFP end-group at the $\alpha$-terminus with $\mathrm{D}-(+)$-galactosamine $\left(\mathrm{GalNH}_{2}\right)$ (Scheme 2$)$. Successful conjugation of galactosamine was confirmed by ${ }^{19}$ F-NMR and FT-IR analysis before and after modification (Fig. S3 and S4, ESI $\dagger$ ). FT-IR spectroscopy confirmed the disappearance of the characteristic bands of PFP-end group at 950 and $1750 \mathrm{~cm}^{-1}$.

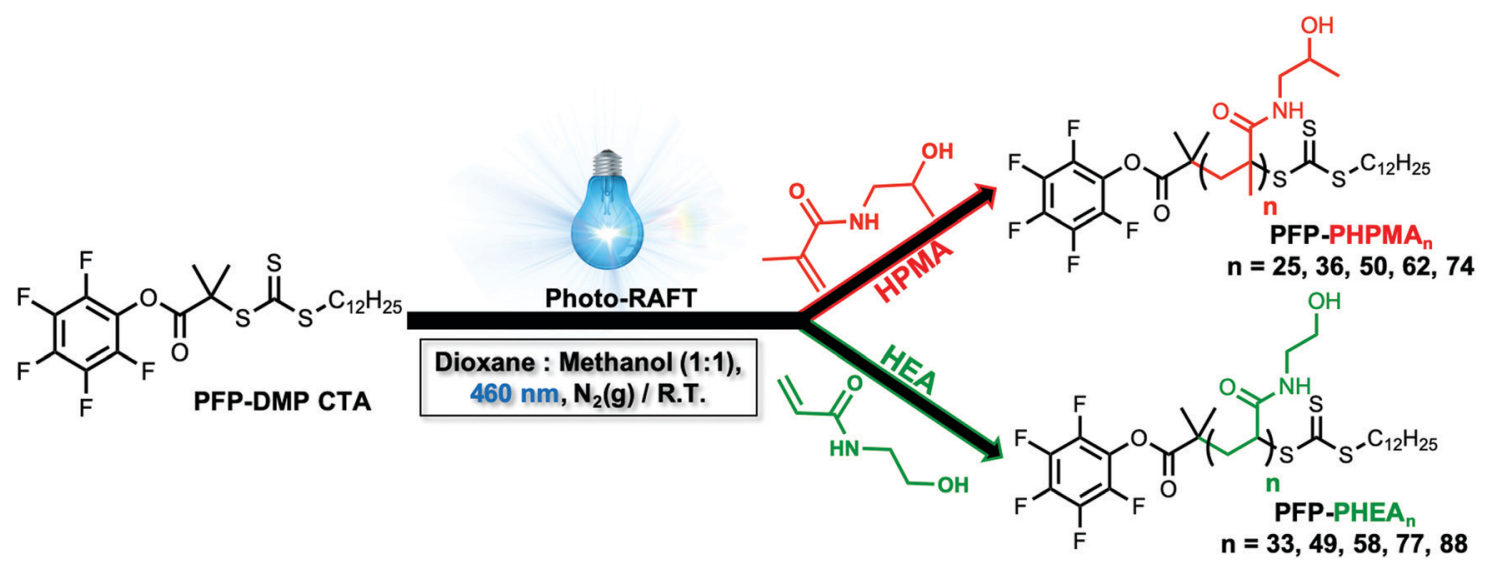

Scheme 1 Schematic of the preparation of poly(N-hydroxypropyl methacrylamide) and poly( $N$-hydroxyethyl acrylamide)-based homopolymers via photo-initiated (460 nm irradiation) reversible addition-fragmentation chain-transfer (photo-RAFT) polymerization at $37^{\circ} \mathrm{C}$. 

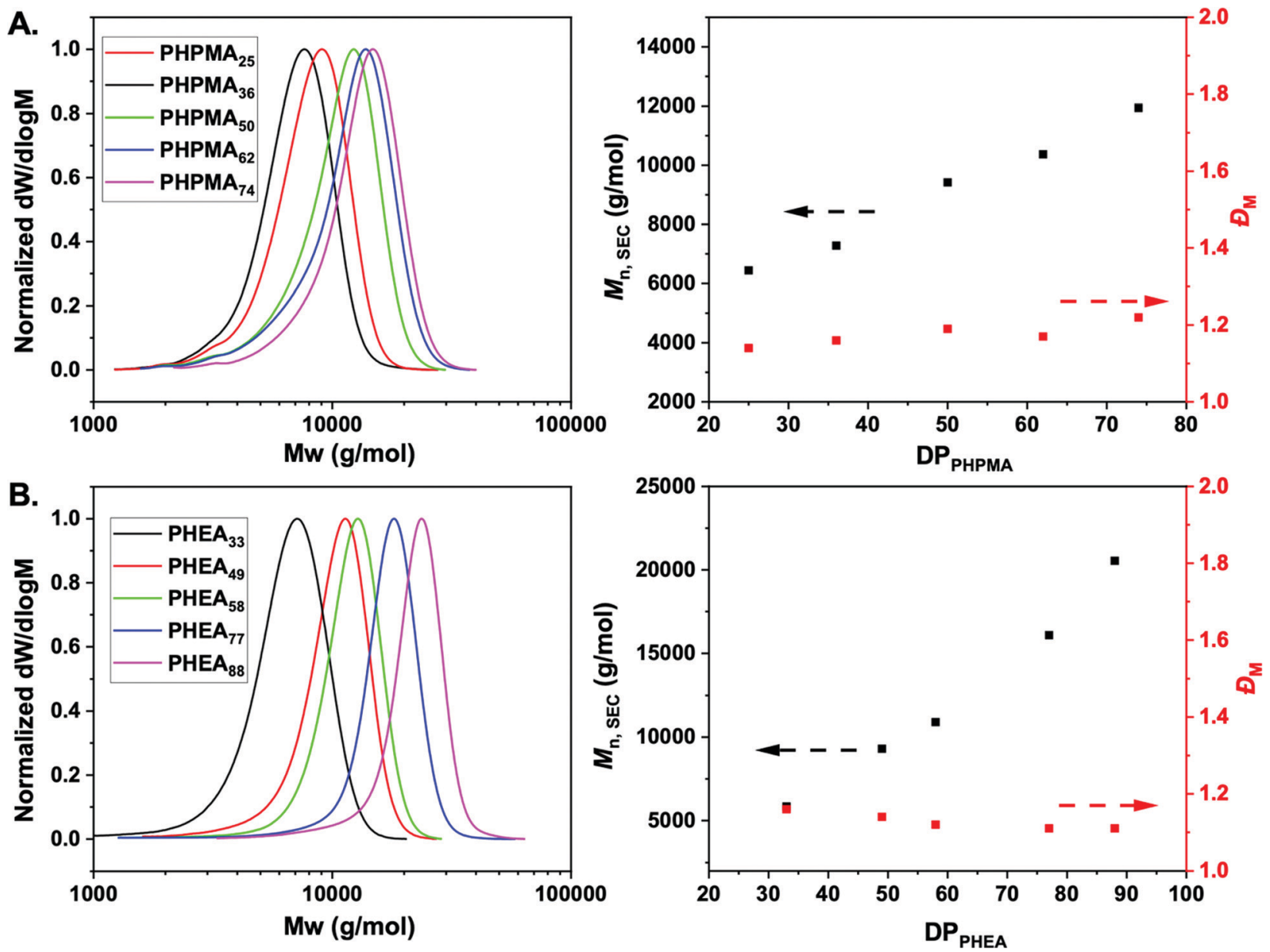

Fig. 1 Size exclusion chromatography analysis. Normalized SEC RI molecular weight distributions (left) for (A) PHPMA and (B) PHEA homopolymers. $M_{n}$ and $\Theta_{M}$ as a function of actual degree of polymerization (DP) for the same polymerizations (right). $M_{n}$ and $\Xi_{M}$ values were calculated from PMMA standards using $5 \mathrm{mM} \mathrm{NH}_{4} \mathrm{BF}_{4}$ in DMF as the eluent.

Table 1 Polymers synthesized by photo-RAFT

\begin{tabular}{lcllll}
\hline & & & & \multicolumn{2}{l}{ SEC } \\
Sample $^{a}$ & {$[\mathrm{M}]:[\mathrm{CTA}]$} & $\begin{array}{l}\text { Conversion } \\
(\%)\end{array}$ & $\begin{array}{l}M_{\mathrm{n}, \mathrm{NMR}^{c}}{ }^{c} \\
\left(\mathrm{~g} \mathrm{~mol}^{-1}\right)\end{array}$ & $\begin{array}{l}M_{\mathrm{n}, \mathrm{SEC}}{ }^{2} \\
\left(\mathrm{~g} \mathrm{~mol}^{-1}\right)\end{array}$ & $D_{\mathrm{M}}{ }^{d}$ \\
\hline PHPMA $_{25}$ & 40 & 63 & 4100 & 6400 & 1.14 \\
PHPMA $_{36}$ & 60 & 60 & 5700 & 7300 & 1.16 \\
PHPMA $_{50}$ & 80 & 61 & 7700 & 9400 & 1.19 \\
PHPMA $_{62}$ & 100 & 62 & 9400 & 10400 & 1.17 \\
PHPMA $_{74}$ & 120 & 62 & 11100 & 11900 & 1.22 \\
PHEA $_{33}$ & 100 & 33 & 4300 & 5800 & 1.16 \\
PHEA $_{49}$ & 140 & 35 & 6200 & 9300 & 1.14 \\
PHEA $_{56}$ & 160 & 35 & 7200 & 10900 & 1.12 \\
PHEA $_{77}$ & 180 & 42 & 9400 & 16100 & 1.11 \\
PHEA $_{88}$ & 200 & 43 & 10700 & 20500 & 1.11
\end{tabular}

${ }^{a}$ Sample names are determined according to the number average degree of polymerization (DP) determined by ${ }^{1} \mathrm{H}$ NMR analysis in methanol- $d_{4} \cdot{ }^{b}$ Monomer conversion calculated by comparing the integrations of the monomer with those of the corresponding signals of the polymer. ${ }^{c} M_{\mathrm{n}, \mathrm{NMR}}$ was calculated by end-group analysis by comparing the integrations of the $-\mathrm{CH}_{3}$ signals $(\delta 0.92 \mathrm{ppm})$ of dodecyl end-group with those of the corresponding signals of the polymer. ${ }^{d} M_{\mathrm{n}}$ and $D_{\mathrm{M}}$ values calculated from PMMA standards using $5 \mathrm{mM} \mathrm{NH}_{4} \mathrm{BF}_{4}$ in DMF as the eluent.

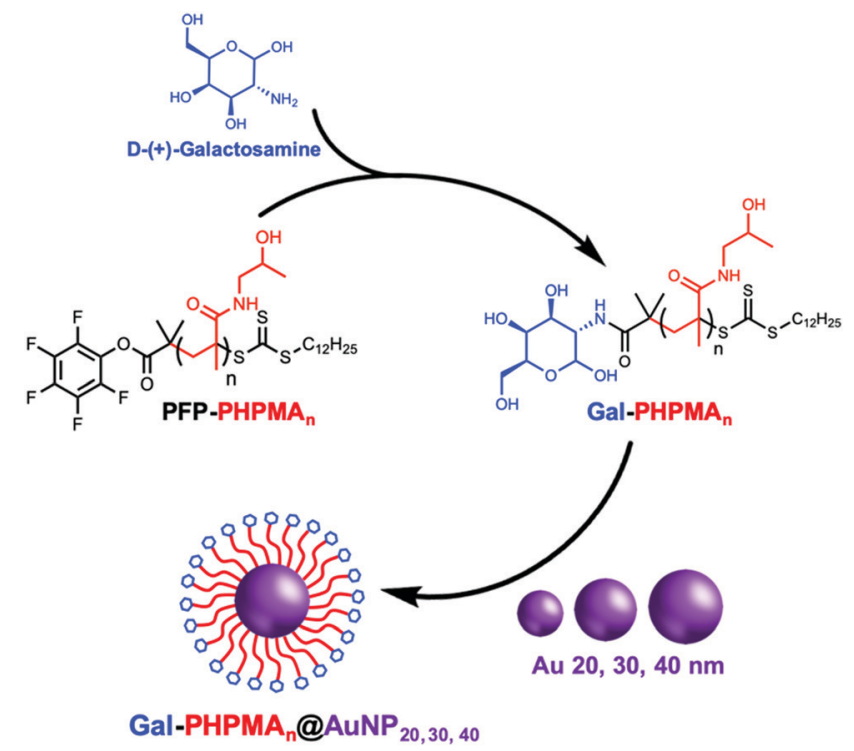

Scheme 2 Preparation of galactosamine-poly(hydroxypropyl methacrylamide) (Gal-PHPMA $n, n=25,36,50,62,74)$ glycopolymers followed by functionalization onto gold nanoparticles surfaces (AuNP) of 20, 30 and $40 \mathrm{~nm}$ diameter. 
20, 30 and $40 \mathrm{~nm}$ citrate-stabilized gold nanoparticles (AuNP) were synthesized by $\mathrm{NaBH}_{4}$ reduction of $\mathrm{HAuCl}_{4}$ following a seeded growth strategy (see $\mathrm{ESI} \dagger$ for detailed synthetic procedure) and subsequently functionalized with thiol-terminated glycopolymers (Gal-PHPMA, Gal-PHEA) by mixing, followed by centrifugation. The resulting polymer-coated nanoparticles were characterized by dry-state transmission electron microscopy (TEM), dynamic light scattering (DLS), zeta-potential and UV-Vis analyses confirming successful addition of the polymer (Table 2 and Table S1, Fig. S5, S6, ESI $\dagger$ ). Dynamic light scattering analysis revealed the polymer coated gold particles had increased hydrodynamic diameters compared with the precursor particles, as would be expected (Table 2). In all cases higher hydrodynamic diameter $\left(D_{\mathrm{h}}\right)$ and polydispersity (PD) values were measured for PHEA-coated NPs compared to PHPMA-coated NPs. UV-vis analysis for the functionalized AuNPs gave similar results, with $\sim 2-3 \mathrm{~nm}$ SPR-shift for both types of polymer.

To further confirm the presence of glycopolymers on the surface of the AuNPs, XPS analysis was performed for a series of $30 \mathrm{~nm}$ Gal-PHPMA/PHEA coated gold nanoparticles (Fig. S7 and S8, ESI $\dagger$ ). The presence of N1s amides, that are not present on the naked particles or found commonly in background contaminants, confirmed successful incorporation of the polymers onto the particle surface (Fig. S9C and S10C, ESI $\dagger$ ).
A deeper consideration of the particle composition ratios, provided by XPS analysis, highlighted higher grafting densities on the nanoparticle surface in the PHEA systems versus the PHPMA systems. This can be seen in the smaller Au 4f:N1s ratios for PHEA (Table S2, ESI $\dagger$ ) compared to the larger PHPMA ratios (Table S3, ESI $\dagger$ ). The ratios further indicate that the PHEA glycopolymers are approximately three-times as prevalent on the gold surface than the PHPMA glycopolymers, when comparing similar chain lengths. Whilst these ratios provide only rough estimates of relative grafting densities it does provide evidence for differing surface grafting behaviors between PHEA and PHPMA and shows how simple modification of the polymer ligand can tune the surface and the observed properties (see below).

It is likely that the Gibbs free energy conformations of the dihedral angles in the polymer backbone are influential in determining grafting density. The PHEA backbone can potentially access lower Gibbs free energy conformers compared to PHPMA due to the additional methyl group in the PHPMA backbone increasing steric hinderance. The radius of gyration of PHPMA would therefore be greater than PHEA, leading to less tight packing in PHPMA. In the context of Hill et al. ${ }^{65}$ this means that the deflection angle of PHPMA is greater than PHEA so has a lower grafting density. This likely explains the molecular weight

Table 2 Polymer-coated gold nanoparticle characterization

\begin{tabular}{|c|c|c|c|c|}
\hline Particle & $\mathrm{SPR}_{\text {uncoated }}{ }^{a}(\mathrm{~nm})$ & $\mathrm{SPR}_{\text {polymer coated }}{ }^{a}(\mathrm{~nm})$ & $D_{\mathrm{h}}^{b}(\mathrm{~nm})$ & $\mathrm{PD}^{b}$ \\
\hline Gal-PHPMA $_{25} @ \mathrm{AuNP}_{20}$ & 520 & 523 & $29.7 \pm 0.6$ & $0.43 \pm 0.02$ \\
\hline Gal-PHPMA $_{36} @ A_{\text {NNP }}$ & 520 & 523 & $31.2 \pm 0.3$ & $0.44 \pm 0.01$ \\
\hline Gal-PHPMA $_{62} @ A_{\text {NuNP }}$ & 520 & 523 & $30.2 \pm 0.5$ & $0.55 \pm 0.10$ \\
\hline Gal-PHPMA $_{74} @ A u N_{20}$ & 520 & 524 & $33.6 \pm 0.5$ & $0.40 \pm 0.01$ \\
\hline Gal-PHEA $_{33} @ A u N P_{20}$ & 520 & 523 & $26.3 \pm 0.5$ & $0.55 \pm 0.13$ \\
\hline Gal-PHEA $_{77} @ A_{\text {NNP }} 20$ & 520 & 524 & $52.0 \pm 7.1$ & $0.37 \pm 0.01$ \\
\hline Gal-PHEA $_{88} @ \mathrm{AuNP}_{20}$ & 520 & 523 & $52.3 \pm 1.1$ & $0.38 \pm 0.01$ \\
\hline Bare gold $30 \mathrm{~nm}$ & 525 & - & $28.5 \pm 0.5$ & $0.25 \pm \mathbf{0 . 0 1}$ \\
\hline Gal-PHPMA $_{25} @ A u N P_{30}$ & 525 & 527 & $34.6 \pm 1.1$ & $0.30 \pm 0.03$ \\
\hline Gal-PHPMA $_{36} @ A_{\text {NNP }}$ & 525 & 527 & $36.3 \pm 0.6$ & $0.27 \pm 0.01$ \\
\hline Gal-PHPMA $_{50 @ A u N P} 30$ & 525 & 529 & $35.7 \pm 0.9$ & $0.26 \pm 0.01$ \\
\hline Gal-PHPMA $_{62} @ A_{\text {NNP }}$ & 525 & 528 & $38.3 \pm 1.0$ & $0.26 \pm 0.01$ \\
\hline Gal-PHEA $_{88} @ \mathrm{AuNP}_{30}$ & 525 & 529 & $57.5 \pm 0.8$ & $0.19 \pm 0.01$ \\
\hline Bare gold $40 \mathrm{~nm}$ & 530 & - & $40.8 \pm 0.5$ & $0.26 \pm 0.01$ \\
\hline Gal-PHPMA $_{25} @ \mathrm{AuNP}_{40}$ & 530 & 532 & $38.5 \pm 0.7$ & $0.41 \pm 0.01$ \\
\hline Gal-PHPMA $_{36} @$ AuNP $_{40}$ & 530 & 532 & $39.4 \pm 1.1$ & $0.41 \pm 0.02$ \\
\hline Gal-PHPMA $_{50} @$ AuNP $_{40}$ & 530 & 533 & $40.4 \pm 1.7$ & $0.42 \pm 0.02$ \\
\hline Gal-PHPMA $_{62} @ \mathrm{AuNP}_{40}$ & 530 & 533 & $43.0 \pm 1.3$ & $0.38 \pm 0.01$ \\
\hline Gal-PHPMA $_{74} @$ AuNP $_{40}$ & 530 & 532 & $42.8 \pm 1.0$ & $0.39 \pm 0.01$ \\
\hline Gal-PHEA $_{33} @$ AuNP$_{40}$ & 530 & 531 & $49.4 \pm 0.6$ & $0.22 \pm 0.01$ \\
\hline Gal-PHEA $_{49} @$ AuNP$_{40}$ & 530 & 531 & $53.2 \pm 0.5$ & $0.20 \pm 0.01$ \\
\hline Gal-PHEA $_{58} @$ AuNP $_{40}$ & 530 & 531 & $54.8 \pm 0.3$ & $0.20 \pm 0.01$ \\
\hline Gal-PHEA $_{77} @$ AuNP $_{40}$ & 530 & 531 & $61.5 \pm 0.5$ & $0.18 \pm 0.01$ \\
\hline Gal-PHEA $_{88} @$ AuNP $_{40}$ & 530 & 531 & $66.1 \pm 0.6$ & $0.16 \pm 0.01$ \\
\hline
\end{tabular}

${ }^{a}$ SPR maximum recorded by UV-Vis spectroscopy. ${ }^{b} D_{\mathrm{h}}$ and PD values determined by DLS (the error represents the standard deviation from 5 repeat measurements). 
effect observed in PHEA. To further understand the complexity in this matter, Barner and co-workers, have recently shown how shorter molecular weight polymers more favourably graft to nanoparticles due to radius of gyration $\left(R_{\mathrm{g}}\right)$ effects. ${ }^{66}$ Previous studies from our group also revealed similar motifs upon comparing water soluble RAFT-derived polymers of poly(vinylpyrrolidone) (PVP) and poly(oligoethyleneglycol methacrylate) (POEGMA). XPS revealed that the sterically bulky POEGMA resulted in far lower grafting densities on gold nanoparticles compared with PVP, suggesting a greater degree of exposed gold surfaces. ${ }^{67}$

As a next step, saline stability was evaluated by a $\mathrm{NaCl}$ titration starting from $0.5 \mathrm{M}$, Fig. S11 (ESI $\dagger$ ). This is essential, as aggregation assays using lectins are evaluated (below) and false positives due to colloidal instability need to be removed. It was observed for PHPMA polymers of DP25 AuNPs of 30 and $40 \mathrm{~nm}$ size were unstable and aggregated at high salt $(>0.2 \mathrm{M}$, which is close to physiological $(0.137 \mathrm{M}))$ concentrations (Fig. S13, ESI $\dagger$ ), while all Gal-PHEA-coated particles remained stable for all sizes and DPs. This can be understood in terms of the increased ratio of gold to polymer in case of 30 and $40 \mathrm{~nm}$ AuNPs and considerably lower grafting densities of PHPMA. While longer polymers (predictably) improved saline stability, it is important to consider the effects of having polymers that are too long; these can prevent/slow the rate of aggregation upon addition of the lectins by steric stabilization.

With this library of nanoparticles varying in the nature of the polymer ligand, their binding to lectins could be assessed. Soybean agglutinin (SBA) was chosen as a model lectin as it has particularly high affinity for $N$-acetyl galactosamine, which the galactosamine used here gives a mimic of once conjugated as an amide to the polymer end group. Like many members of the legume lectin family SBA possesses a single carbohydrate binding site that requires $\mathrm{Mn}^{2+}$ or $\mathrm{Ca}^{2+}$ for activity. ${ }^{68}$ However above $\mathrm{pH} 4.6$ (we use $\mathrm{pH} 7.4$ here), SBA is tetrameric allowing for cross-linking and agglutination. ${ }^{69,70}$ This makes SBA an attractive analyte model lectin for testing glycopolymer-based systems and saccharides for diagnostics of particular interest. ${ }^{71}$

Initially, the particles were incubated in buffer with SBA from $0-1 \mathrm{mg} \mathrm{mL}{ }^{-1}$. A red-blue color change occurs upon aggregation of gold nanoparticles (Fig. S14 and S15, ESI $\dagger$ ) due to coupling of their SPR bands enabling easy read out of aggregation (and indirectly of glycan-lectin binding). Fig. 2 shows the change in absorbance at $700 \mathrm{~nm}\left(\mathrm{AbS}_{700}\right)$ (normalised against the SPR maxima) as a function of SBA for each particle. Rather interestingly, in the case of Gal-PHPMA particles there was no significant increase in $\mathrm{Abs}_{700}$ at any concentration for all the particles, with
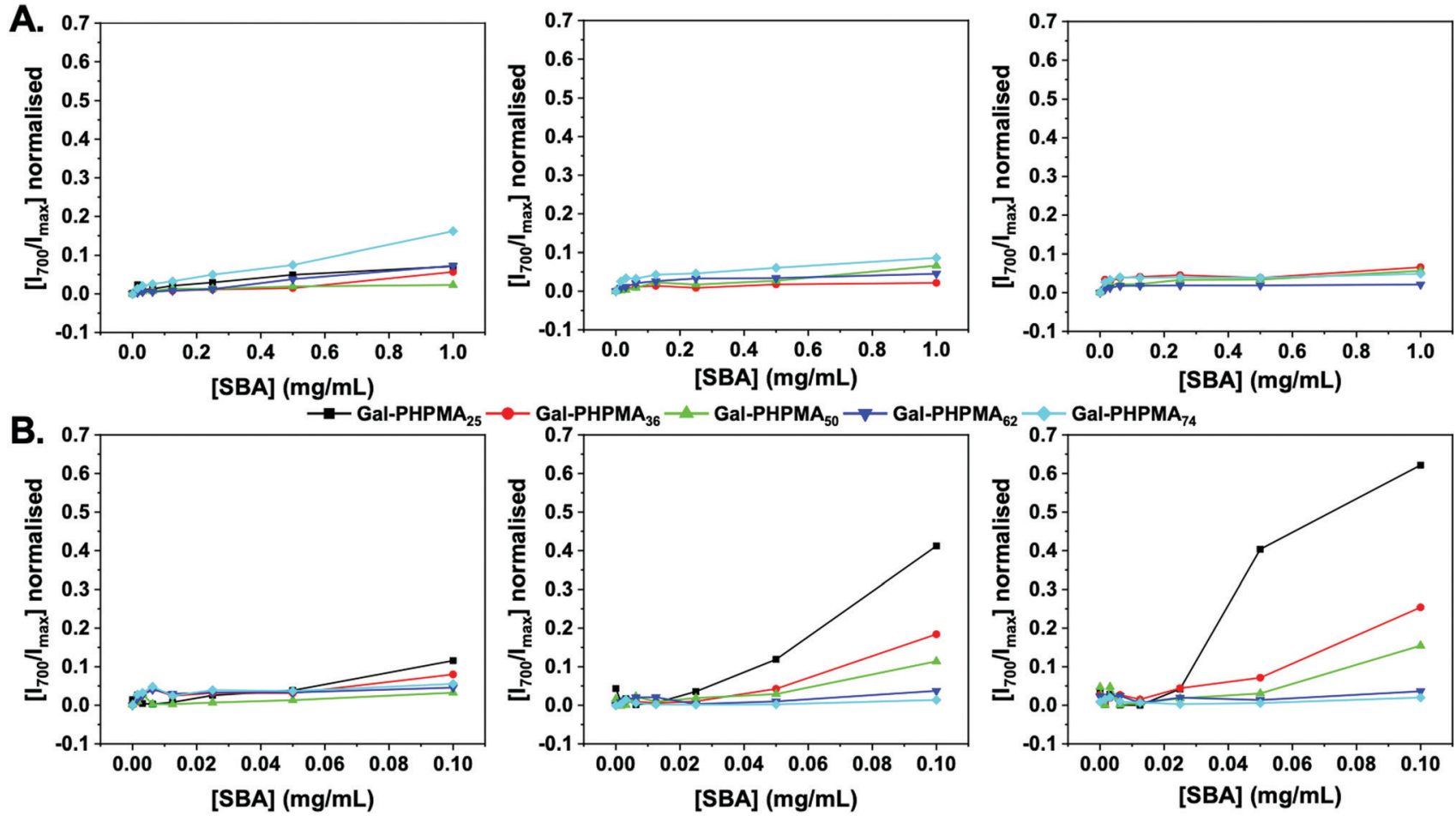

$\rightarrow-$ Gal-PHEA $_{33} \longrightarrow$ Gal-PHEA $_{49} \longrightarrow$ Gal-PHEA $_{58} \rightarrow-$ Gal-PHEA $_{77} \longrightarrow$ Gal-PHEA $_{88}$

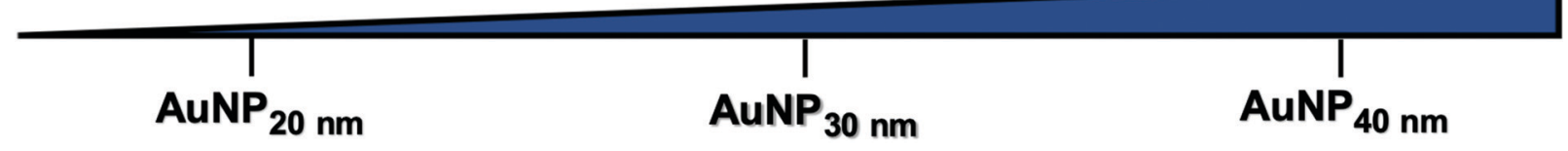

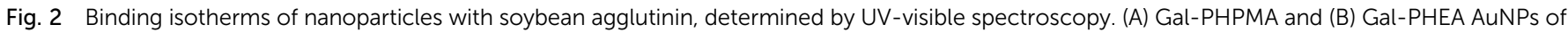

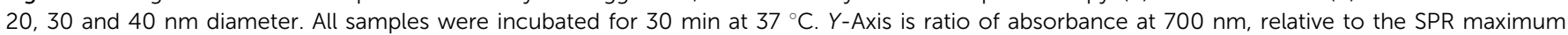
wavelength of the AuNPs. 
the exception for Gal-PHPMA ${ }_{74}$ coated particles which had a (small) shift at the highest SBA concentration. Normally, this would be interpreted as 'binding not occurring' and indeed there exist many examples of polymer systems where turbidimetry is used as the output for glycan binding. ${ }^{72-74}$ However, it is perfectly feasible that binding can occur without cross-linking depending on the architecture of the glycans. ${ }^{75}$ Fig. $2 \mathrm{~B}$ shows the same experiment but using particles coated with Gal-PHEA. In this case, there was rapid aggregation and clear dose-dependent binding across the entire series. Smaller nanoparticles resulted in less aggregation, as did longer polymer linkers, in line with previous
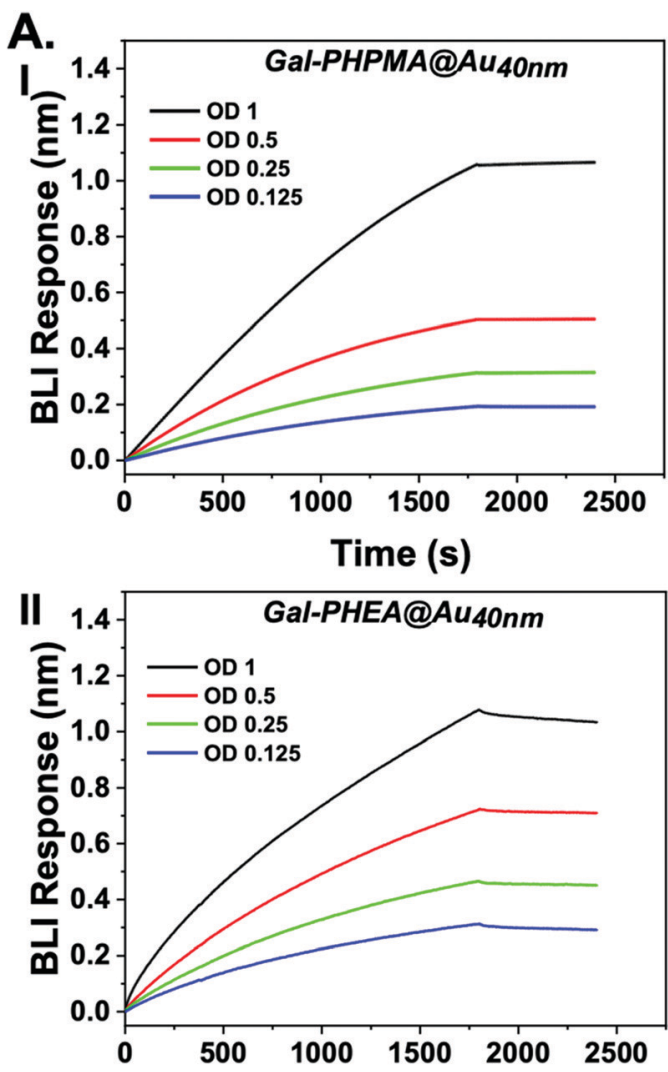

B.

Time (s)

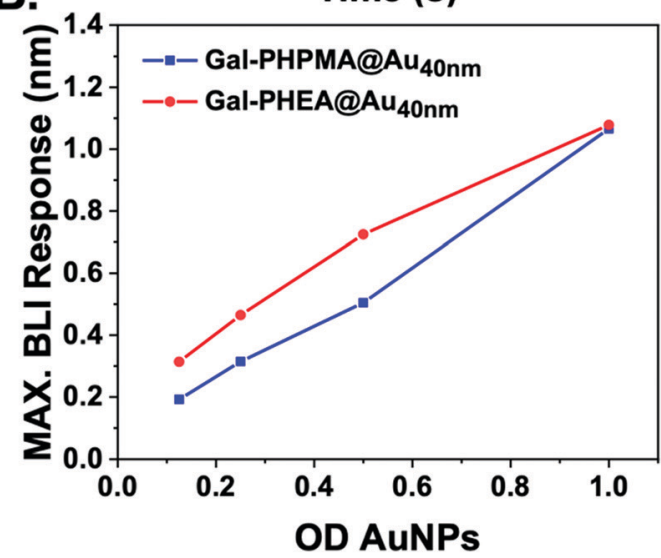

Fig. 3 Biolayer interferometry analysis of nanoparticles binding to immobilized SBA. (A) Response of (I) Gal-PHPMA ${ }_{36} @_{A} \mathrm{AuNP}_{40}$ and Gal$\mathrm{PHEA}_{33} \mathrm{CAUNP}_{40}$; (B) maximum BLI response vs. AuNP concentration. observations. ${ }^{45}$ This experiment clearly showed that the polymer ligand, as well as the actual glycan, is a key component in the outputs of nanoparticle based sensing systems and needs to be fine-tuned to achieve appropriate outputs.

To ensure that the above observations (no aggregation of Gal-PHPMA) was not due to inaccessibility of the glycan we used a complementary technique to assess lectin binding. Biolayer interferometry (BLI) was used as a label-free, masssensitive method for evaluating biomolecular interactions. ${ }^{76,77}$ The technology is based on the refraction of white light from two surfaces: a layer of immobilized protein on a biosensor tip, and an internal reference layer. Surface binding to the biosensor tip causes a shift in the interference pattern that can be measured in real-time. ${ }^{78}$

SBA was modified with biotin-NHS, and immobilized onto streptavidin BLI sensors. Then two different particles were evaluated for dose-dependent binding to the SBA. Gal$\mathrm{PHPMA}_{36} @ \mathrm{AuNP}_{40}$ was found not to aggregate in the studies, above, but Gal-PHEA ${ }_{33} @$ AuNP $_{40}$ did, enabling us to probe if lack of aggregation could rule out binding. Fig. 3 shows the binding data, clearly showing that both particles have affinity towards the SBA with similar dose-response curves being obtained. [Note, kinetic analysis is not possible due to the high valency of these particles.] This experiment proves that the two polymer coatings both present sufficient Gal for strong SBA binding but that the PHPMA coating prevents aggregation from occurring, whereas PHEA encourages it. Taken together this study demonstrates that the chemical nature, as well as the molecular weight, of the polymer linker has a dramatic impact on the outcomes of glyconanoparticle sensing platforms, enabling control over aggregative versus non-aggregative outputs and will help design robust nano-biosensors in the future.

\section{Conclusions}

Here we demonstrate the crucial impact that the chemical nature, not just the molecular weight, of polymer linkers have in the design of glyconanoparticle sensors. Photo-initiated RAFT polymerization was used to obtain well-defined poly( $N$-hydroxypropyl methacrylamide), PHPMA and poly( $N$-hydroxyethyl acrylamide), PHEA bearing pentafluorophenyl ester end groups. Following introduction of a galactosamine unit at the chain ends, the polymers were assembled on 20 to $40 \mathrm{~nm}$ gold nanoparticle cores using the terminal thiol group, to give a library of 30 nanoparticles varying in chain length, core size and either a methacrylate or acrylate polymeric backbone. Aggregation assays of these particles using a model lectin showed that, as previously reported, PHEA led to significant aggregation due to lectin-induced cross linking. However, PHPMA nanoparticles showed essentially no response to the lectin, which in traditional aggregation assays would be interpreted as a negative (no binding) result which we show to be incorrect. Using a complementary biolayer interferometrybased assay, it was shown that both types of coatings actually lead to similar lectin binding affinity, even though in the 
colorimetric aggregation assay there were significant differences. This provides robust evidence that the PHPMA coating approach can prevent aggregation but still present glycans in a manner for lectin binding. XPS showed that the subtle change from acrylamide to methacrylamide changed the grafting density with PHPMA having fewer chains/particle at any given chain length than PHEA, which may contribute to these observations. Overall, the data presented here provides conclusive evidence that the polymer linker itself can play a crucial role in controlling the outputs of glycosylated gold nanoparticles and enable tuning between aggregative and non-aggregative states whilst retaining binding affinity. This simple approach enables selection of the two outputs, depending on the assay or application area (e.g. in vivo versus ex vivo), without requiring significant changes to the design strategy or the glycan conjugation.

\section{Conflicts of interest}

There are no conflicts to declare.

\section{Acknowledgements}

This project has received funding from the European Union's Horizon 2020 research and innovation programme under the Marie Skłodowska-Curie grant agreement no. 814236. MIG holds an ERC starting grant (CRYOMAT 638661). The Royal Society are thanked for funding the cryo-microscopes used in this study. BBSRC/Innovate are thanked for funding the Specialty Glycans project BB/M02878X/1. The BBSRC-funded MIBTP program (BB/M01116X/1) and Iceni Diagnostics ltd are also thanked for a studentship for AB. The Warwick Polymer Research Technology Platform is acknowledged for SEC analysis.

\section{Notes and references}

1 S. S. Pinho and C. A. Reis, Nat. Rev. Cancer, 2015, 15, 540-555.

2 C. R. Bertozzi and L. L. Kiessling, Science, 2001, 291, 2357-2364.

3 C. D. Rillahan and J. C. Paulson, Annu. Rev. Biochem., 2011, 80, 797-823.

4 J. J. Lundquist and E. J. Toone, Chem. Rev., 2002, 102, 555-578.

5 M. Ambrosi, N. R. Cameron and B. G. Davis, Org. Biomol. Chem., 2005, 3, 1593-1608.

6 G. B. Sigal, M. Mammen, G. Dahmann and G. M. Whitesides, J. Am. Chem. Soc., 1996, 118, 3789-3800.

7 M. L. Huang, M. Cohen, C. J. Fisher, R. T. Schooley, P. Gagneux and K. Godula, Chem. Commun., 2015, 51, 5326-5329.

8 B. D. Polizzotti and K. L. Kiick, Biomacromolecules, 2006, 7, 483-490.

9 S.-J. Richards, M. W. Jones, M. Hunaban, D. M. Haddleton and M. I. Gibson, Angew. Chem., Int. Ed., 2012, 51, 7812-7816.
10 S. Zhang, R.-O. Moussodia, S. Vértesy, S. André, M. L. Klein, H.-J. Gabius and V. Percec, Proc. Natl. Acad. Sci. U. S. A., 2015, 112, 5585-5590.

11 T. R. Branson and W. B. Turnbull, Chem. Soc. Rev., 2013, 42, 4613-4622.

12 S. G. Spain, M. I. Gibson and N. R. Cameron, J. Polym. Sci., Part A: Polym. Chem., 2007, 45, 2059-2072.

13 S. R. S. Ting, G. Chen and M. H. Stenzel, Polym. Chem., 2010, 1, 1392-1412.

14 M. L. Huang, R. A. A. Smith, G. W. Trieger and K. Godula, J. Am. Chem. Soc., 2014, 136, 10565-10568.

15 J. Conniot, A. Scomparin, C. Peres, E. Yeini, S. Pozzi, A. I. Matos, R. Kleiner, L. I. F. Moura, E. Zupančič, A. S. Viana, H. Doron, P. M. P. Gois, N. Erez, S. Jung, R. Satchi-Fainaro and H. F. Florindo, Nat. Nanotechnol, 2019, 14, 891-901.

16 S. Srinivasachari, Y. Liu, G. Zhang, L. Prevette and T. M. Reineke, J. Am. Chem. Soc., 2006, 128, 8176-8184.

17 M. Moros, B. Hernáez, E. Garet, J. T. Dias, B. Sáez, V. Grazú, Á. González-Fernández, C. Alonso and J. M. de la Fuente, ACS Nano, 2012, 6, 1565-1577.

18 M. Marradi, F. Chiodo, I. García, S. Penadés, G. M. Whitesides, D. Y. Lee, H. Shin, R. J. Pieters, J. M. de la Fuente, S.-H. Nishimura, P. Arosio, A. Lascialfari, D. Gatteschi and C. Sangregorio, Chem. Soc. Rev., 2013, 42, 4728-4745.

19 N.-C. Reichardt, M. Martín-Lomas and S. Penadés, Chem. Commun., 2016, 52, 13430-13439.

20 C. Van Bruggen, J. K. Hexum, Z. Tan, R. J. Dalal and T. M. Reineke, Acc. Chem. Res., 2019, 52, 1347-1358.

21 S. Bhatia, L. C. Camacho and R. Haag, J. Am. Chem. Soc., 2016, 138, 8654-8666.

22 P. I. Kitov, J. M. Sadowska, G. Mulvey, G. D. Armstrong, H. Ling, N. S. Pannu, R. J. Read and D. R. Bundle, Nature, 2000, 403, 669-672.

23 M. Mammen, G. Dahmann and G. M. Whitesides, J. Med. Chem., 1995, 38, 4179-4190.

24 M. W. Jones, L. Otten, S.-J. Richards, R. Lowery, D. J. Phillips, D. M. Haddleton and M. I. Gibson, Chem. Sci., 2014, 5, 1611-1616.

25 T. R. Branson, T. E. McAllister, J. Garcia-Hartjes, M. A. Fascione, J. F. Ross, S. L. Warriner, T. Wennekes, H. Zuilhof and W. B. Turnbull, Angew. Chem., Int. Ed., 2014, 53, 8323-8327.

26 E. Kolomiets, M. A. Swiderska, R. U. Kadam, E. M. V. Johansson, K. E. Jaeger, T. Darbre and J. L. Reymond, ChemMedChem, 2009, 4, 562-569.

27 C. R. Becer, M. I. Gibson, J. Geng, R. Ilyas, R. Wallis, D. A. Mitchell and D. M. Haddleton, J. Am. Chem. Soc., 2010, 132, 15130-15132.

28 S. Ordanini, N. Varga, V. Porkolab, M. Thépaut, L. Belvisi, A. Bertaglia, A. Palmioli, A. Berzi, D. Trabattoni, M. Clerici, F. Fieschi and A. Bernardi, Chem. Commun., 2015, 51, 3816-3819.

29 C. M. Jarvis, D. B. Zwick, J. C. Grim, M. M. Alam, L. R. Prost, J. C. Gardiner, S. Park, L. L. Zimdars, N. M. Sherer and 
L. L. Kiessling, Proc. Natl. Acad. Sci. U. S. A., 2019, 116, 14862-14867.

30 R. Jelinek and S. Kolusheva, Chem. Rev., 2004, 104, 5987-6016.

31 S. Cunningham, J. Q. Gerlach, M. Kane and L. Joshi, Analyst, 2010, 135, 2471-2480.

32 X. Huang and M. A. El-Sayed, J. Adv. Res., 2010, 1, 13-28.

33 L. Dykman and N. Khlebtsov, Chem. Soc. Rev., 2012, 41, 2256-2282.

34 Z. Yuan, C.-C. Hu, H.-T. Chang and C. Lu, Analyst, 2016, 141, 1611-1626.

35 C. J. Murphy, A. M. Gole, J. W. Stone, P. N. Sisco, A. M. Alkilany, E. C. Goldsmith and S. C. Baxter, Acc. Chem. Res., 2008, 41, 1721-1730.

36 C. A. Mirkin, R. L. Letsinger, R. C. Mucic and J. J. Storhoff, Nature, 1996, 382, 607-609.

37 D. C. Hone, A. H. Haines and D. A. Russell, Langmuir, 2003, 19, 7141-7144.

38 C. L. Schofield, R. A. Field and D. A. Russell, Anal. Chem., 2007, 79, 1356-1361.

39 M. J. Marín, A. Rashid, M. Rejzek, S. A. Fairhurst, S. A. Wharton, S. R. Martin, J. W. McCauley, T. Wileman, R. A. Field and D. A. Russell, Org. Biomol. Chem., 2013, 11, 7101.

40 M. Takara, M. Toyoshima, H. Seto, Y. Hoshino and Y. Miura, Polym. Chem., 2014, 5, 931-939.

41 S. O. Pereira, A. Barros-Timmons and T. Trindade, Polymers, 2018, 10, 189.

42 M. Beija, J.-D. Marty and M. Destarac, Prog. Polym. Sci., 2011, 36, 845-886.

43 C. Boyer, V. Bulmus, T. P. Davis, V. Ladmiral, J. Liu and S. Perrier, Chem. Rev., 2009, 109, 5402-5436.

44 G. Moad, E. Rizzardo and S. H. Thang, Acc. Chem. Res., 2008, 41, 1133-1142.

45 S.-J. Richards and M. I. Gibson, ACS Macro Lett., 2014, 3, 1004-1008.

46 S.-J. Richards, E. Fullam, G. S. Besra and M. I. Gibson, J. Mater. Chem. B, 2014, 2, 1490-1498.

47 S.-J. Richards, L. Otten and M. I. Gibson, J. Mater. Chem. B, 2016, 4, 3046-3053.

48 L. Otten, D. Vlachou, S.-J. Richards and M. I. Gibson, Analyst, 2016, 141, 4305-4312.

49 S. Won, S. Hindmarsh and M. I. Gibson, ACS Macro Lett., 2018, 7, 178-183.

50 B. S. Tucker and B. S. Sumerlin, Polym. Chem., 2014, 5, 1566-1572.

51 M. Talelli, C. J. F. Rijcken, C. F. van Nostrum, G. Storm and W. E. Hennink, Adv. Drug Delivery Rev., 2010, 62, 231-239.

52 R. Duncan and M. J. Vicent, Adv. Drug Delivery Rev., 2010, 62, 272-282.

53 J. Kopeček, Adv. Drug Delivery Rev., 2013, 65, 49-59.
54 K. Ulbrich and V. Šubr, Adv. Drug Delivery Rev., 2010, 62, 150-166.

55 J. Geng, W. Li, Y. Zhang, N. Thottappillil, J. Clavadetscher, A. Lilienkampf and M. Bradley, Nat. Chem., 2019, 11, 578-586.

56 V. Raus and L. Kostka, Polym. Chem., 2019, 10, 564-568.

57 N. Francini, L. Purdie, C. Alexander, G. Mantovani and S. G. Spain, Macromolecules, 2015, 48, 2857-2863.

58 P. Bojarová, P. Chytil, B. Mikulová, L. Bumba, R. Konefał, H. Pelantová, J. Krejzová, K. Slámová, L. Petrásková, L. Kotrchová, J. Cvačka, T. Etrych and V. Křen, Polym. Chem., 2017, 8, 2647-2658.

59 D. Roy, B. Ghosn, E.-H. Song, D. M. Ratner and P. S. Stayton, Polym. Chem., 2013, 4, 1153-1160.

60 M. Bartneck, C. T. Schlößer, M. Barz, R. Zentel, C. Trautwein, T. Lammers and F. Tacke, ACS Nano, 2017, 11, 9689-9700.

61 J. T. Lai, D. Filla and R. Shea, Macromolecules, 2002, 35, 6754-6756.

62 S. Won, S.-J. Richards, M. Walker and M. I. Gibson, Nanoscale Horiz., 2017, 2, 106-109.

63 S. Yamago and Y. Nakamura, Polymer, 2013, 54, 981-994.

64 T. G. McKenzie, Q. Fu, M. Uchiyama, K. Satoh, J. Xu, C. Boyer, M. Kamigaito and G. G. Qiao, Adv. Sci., 2016, 3, 1500394.

65 H. D. Hill, J. E. Millstone, M. J. Banholzer and C. A. Mirkin, ACS Nano, 2009, 3, 418-424.

66 L. Michalek, K. Mundsinger, C. Barner-Kowollik and L. Barner, Polym. Chem., 2019, 10, 54-59.

67 N. Sze Ieong, C. I. Biggs, M. Walker and M. I. Gibson, J. Polym. Sci., Part A: Polym. Chem., 2017, 55, 1200-1208.

68 V. S. R. Rao, K. Lam and P. K. Qasba, J. Biomol. Struct. Dyn., 1998, 15, 853-860.

69 M. Huet, Eur. J. Biochem., 1975, 59, 627-632.

70 D. K. Mandal, E. Nieves, L. Bhattacharyya, G. A. Orr, J. Roboz, Q.-t. Yu and C. F. Brewer, Eur. J. Biochem., 1994, 221, 547-553.

71 B. Ernst and J. L. Magnani, Nat. Rev. Drug Discovery, 2009, 8, 661 .

72 M. Kanai, K. H. Mortell and L. L. Kiessling, J. Am. Chem. Soc., 1997, 119, 9931-9932.

73 M. W. Jones, S.-J. Richards, D. M. Haddleton and M. I. Gibson, Polym. Chem., 2013, 4, 717-723.

74 R. Sunasee and R. Narain, Macromol. Biosci., 2013, 13, 9-27. 75 K. Godula and C. R. Bertozzi, J. Am. Chem. Soc., 2012, 134, 15732-15742.

76 Y. Ji and R. J. Woods, Glycobiology, Springer, Singapore, 2018, pp. 259-273.

77 L. E. Wilkins, N. Badi, F. Du Prez and M. I. Gibson, ACS Macro Lett., 2018, 7, 1498-1502.

78 H.-M. Schmitt, A. Brecht, J. Piehler and G. Gauglitz, Biosens. Bioelectron., 1997, 12, 809-816. 